Journal of Engineering and Applied Sciences 14 (Special Issue 5): 8978-8990, 2019

ISSN: 1816-949X

(C) Medwell Journals, 2019

\title{
Effect of Plasma Nitriding on Wear Behavior of Ni-B-CNT Electroless Coating of AISI 4340
}

\author{
${ }^{1}$ Abdul Raheem K.AbidAli, ${ }^{2}$ Farzad Mahoubi and ${ }^{3}$ Alaa Mohammed Hussein Wais \\ ${ }^{1}$ Al-Mustaqbal University College, Iraq \\ ${ }^{2}$ University of Babylon, Iraq \\ ${ }^{3}$ Amirkabir University of Technology, Iran
}

\begin{abstract}
The present work aims to study the hardness and wear resistance of as-plated and plasma-nitrided electroless Ni-B-CNT coatings. electroless Ni-B coatings. Ni-B-CNT composite was deposited on AISI 4340 steel using different concentration of CNTs ranging, $0,0.35$ and $0.7 \mathrm{~g} \mathrm{~L}^{-1}$ in an electroless bath. After the plating process, all samples were plasma nitrided in an atmosphere comprising of $50 \% \mathrm{~N}_{2}-50 \% \mathrm{H}_{2}$, at $400{ }^{\circ} \mathrm{C}$, for $4 \mathrm{~h}$. The friction and wear behavior of the composite coatings were evaluated using a pin on disk method at an applied load of $10 \mathrm{~N}$. An alkaline bath having nickel chloride as the source of nickel, borohydride as the reducing agent and Multi walled carbon nanotubes (MWCNT)was used to prepare the electroless Ni-B-CNT coatings. The samples were then characterized by means of XRD, FESEM, microhardness and surface roughness measurements. Worn surfaces were further analyzed by FESEM and EDS spectroscopy. Microhardness results revealed that the maximum hardness of $1250 \mathrm{HV}$ was obtained for Ni-B $0.35 \mathrm{~g} \mathrm{~L}^{-1} \mathrm{CNT}$ plasma-nitrided sample. According to the results, increasing the CNTs concentration caused the as-plated Ni-B amorphous structure to change to crystalline. Presence of CNTs not only decreased the grain size in the plasma-nitrided samples but also prevented excessive heat generation during the wear test and thus the friction coefficient was declined during the test. Moreover, image of the worn surface of Ni-B $0.35 \mathrm{~g} \mathrm{~L}^{-1}$ CNT plasma-nitrided sample indicated the smoothest wear trace with no apparent cracks and the highest wear resistance among all the samples was achieved. While, in Ni-B- $0.7 \mathrm{~g} \mathrm{~L}^{-1} \mathrm{CNT}$ sample, agglomeration created asperities as well as large particles weakly bonded to the Ni matrix which ultimately led to an increase in the specific wear rate.
\end{abstract}

Key words: Electroless Ni-B-CNT coating, plasma nitriding, microhardness, wear resistance

\section{INTRODUCTION}

Recently, coating process making use of aqueous solutions (electroplating and electroless plating) have gained significant consideration because of their salient benefits such as ease of the coating process, low cost, high deposition rate, formation of uniform coating layer and promising final properties such as high hardness, amazing wear resistance and decent anticorrosion properties (Boccaccini and Zhitomirsky, 2002; Thiemig and Bund, 2008; Liu and Gao, 2006; Wu et al., 2010). Among aqueous solution metal deposition processes, electroless nickel coating process is more popular and has experienced remarkable modifications since its invention by Brenner and Riddell (1946). This process possess some distinct collection of properties such as uniform thickness, high hardness, good wear and abrasion resistance, excellent corrosion resistance, good solderability, amorphous and/or microcrystalline deposit, low coefficient of friction, high reflectivity, low resistivity and good magnetic properties etc. Their work led to the development of the 'kanigen' process (catalytic nickel generation) by the General American Transportation Corp (G.A.T.C.) which lauched a pilot line in 1955 (Riedel, 1989). The first borohydride reduced bath was proposed in 1954 and the technology was developed in 1957-1958, less than 20 years after the first synthesis of sodium borohydride (Schlesinger and Brown, 1945). Electroless coatings are finding their applications in many areas like MEMS, electromagnetic interference (EMI), powder metallurgy, reactor membranes, heat exchangers and reduction of bacterial adhesion. The thickness uniformity is an outstanding advantage of electroless coating process when compared with the electrodeposition process (Sahoo and Das, 2011; Yang etal., 2011; Afroukhteh et al., 2012; Li et al., 2013). Considering the apparent benefits of boron and promising advantages of electroless coating process, improvement of surface properties by depositing Ni-B coating through electroless coating process can be regarded as a reasonable choice. After its maturity, scalability and repeatability in 1989, the Ni-B electroless coating process was adopted as a mass production process. Since then the electroless Ni-B coating process is gaining remarkable attention to improve the surface

Corresponding Author: Abdul Raheem K.AbidAli, Al-Mustaqbal University College, Iraq 


\section{J. Eng. Applied Sci., 14 (Special Issue 5): 8978-8990, 2019}

properties of a large variety of substrates (Vitry et al., 2012; Riddle and Bailerare, 2005). Electroless Ni-B coating process produces uniform coatings containing appreciable amount of nickel boride which induces substantial improvement in wear and abrasion properties (Narayanan et al., 2004; Krishnaveni et al., 2005; Wang et al., 2012). A large variety of substrate materials can be employed including carbon steels, stainless steels, iron, aluminium and aluminium alloys, glasses, plastics, etc. The outstanding benefits of electroless Ni-B coatings include their high hardness (higher than tool steels), excessive wear resistance (superior as compared to hard chromium coatings) and promising corrosion resistant properties (Ni-P coatings). Instead of above mentioned advantages, low cost, uniform thickness, high wear resistance, good lubricity, promising ductility and corrosion resistance, marvelous solderability, high electrical properties, small porosity, high bonding, good conductivity, outstanding electromagnetic properties are added merits of electroless Ni-B coatings (Bulbul et al., 2012). Generally, electroless Ni-B coating process is believed to be better as compared to Ni-P plating and is becoming much attractive for many industries (Xuan et al., 2006; Hassan and Hamid, 2011). The most common method to induce crystallization and enhance the coating hardness after the deposition process, is heat treatment in 95\% Ar-5\% H2 atmosphere (Vitry et al., 2011; Georgiza et al., 2017). Only a handful of researchers have studied Ni-B heat treatment in a vacuum and nitriding atmosphere (Vitry et al., 2012). To achieve enhanced mechanical properties, corrosion resistance and wear resistance, composite and nanocomposite coatings have attracted a great deal of attention. Hard particles like diamond (Monteiro et al., 2015), TiO2 (Niksefat and Ghorbani, 2015) and WC (Wu et al., 2004) have been widely applied in composite coatings in recent years. Another category of composite or nanocomposite coating is known as solid lubricants such as MoS2 (He et al., 2016), PTFE (Wan et al., 2016) and CNT (Carpenter et al., 2011) which could serve to decrease the coefficient of friction and improve the wear resistance of the surface. Carbon nanotubes (CNTs) are graphene sheets rolled into cylinders. The walls of the tubes are hexagonal carbon with strong SP2 covalent carbon bonds and the end caps contain pentagonal rings (Hatipoglu et al., 2016). Owing to their strikingly high tensile strength and elastic modulus (Yu et al., 2000), they have attracted abundant attention in the field of metallic composites and ceramic composites and have been applied in Cu-CNT (Tsai et al., 2017), ZrO2-CNT
(Melk et al., 2015) and Ni-P-CNT (Wang et al., 2016). Mechanical treatments like ball-milling process and chemical treatment, including adding polymers, surfactants and oxidation of the CNTs, are the most common approaches taken to tackle their poor dispersion issue (Puchy et al., 2013; Munkhbayar et al., 2012). Surfactants are divided into the ionic and non-ionic groups. The ionic category, including anionic and cationic groups, creates repulsion force between the CNTs and therefore, their dispersibility grows. Application of non-ionic surfactants due to their hydrophilic ends is also considered for improving CNTs dispersibility (Zhou et al., 2018).

The aim of the present study is to understand the effect of plasma nitriding treatment on the wear behavior of Ni-B-CNT electroless deposition. Furthermore, the effects of different concentrations of CNTs on the microhardness, crystallographic structure and wear behavior of the as-plated and plasma-nitrided samples were investigated.

\section{Experimental}

Substrate preparation: The substrate metal used in this work was 4340 steel. specimens $(20 \mathrm{~mm}$ diam eter $\times 10 \mathrm{~mm}$ height) were used as the substrates. The chemical analysis for this alloyand Details composition (weight \%) is shown in Table 1 .

In order to improve the mechanical properties such as hardness and toughness, the substrates were subjected to heat treatment (hardening and tempering), heating to $850^{\circ} \mathrm{C}$ for one hour followed by oil quenching. Then, they were tempered at in temperature $400^{\circ} \mathrm{C}$ for one hour, then cooling in air to room temperature. All specimens were grinded and polished as ASTM by emery paper (tungsten oxide paper) No. 180-2000, Then samples were washed by distilled water and ethanol and dried by using an electrical dryer. A polishing was conducted by diamond paste, Specimens were immersion in acetone for $30 \mathrm{~min}$, Before coating, Specimens were immersion in solution include materials $\left(30 \mathrm{~g} \mathrm{~L}^{-1} \mathrm{NaOH}, 60 \mathrm{~g} \mathrm{~L}^{-1} \mathrm{NaCO}_{3}\right.$ and $60 \mathrm{~g} \mathrm{~L}^{-1} \mathrm{NaPbo}_{4}$ for $1 \mathrm{~min}$ period at $60^{\circ} \mathrm{C}$ temperature with moving the electrolyte using magnetic stirring by supply power ( 5 volt) to remove any dust and oil from the surface of the metal, after that the specimens were washed with distilled water, the specimens were dried by using an electrical dryer and after that, it directed immersion in coating solution and After that, the specimens were dried by using an electrical dryer, as well the samples were placed in glass storage (desiccator) which contains particles of silca gel for absorbing wetness to protect the specimens from corrosion.

Table 1: Chemical compositions of 4340 steel

\begin{tabular}{llllllllll}
\hline Elements & $\mathrm{C}$ & $\mathrm{Si}$ & $\mathrm{S}$ & $\mathrm{Mn}$ & $\mathrm{P}$ & $\mathrm{Cr}$ & $\mathrm{Ni}$ & $\mathrm{Mo}$ \\
\hline AISI & $0.3-0.45$ & $0.2-0.4$ & $\mathrm{Max} 0.04$ & $0.5-0.8$ & $\mathrm{Max} 0.04$ & $0.6-0.9$ & $1.25-1.75$ & $0.15-0.25$ & $\mathrm{Bal}$ \\
W\% & 0.36 & 0.29 & 0.01 & 0.67 & 0.01 & 0.81 & 1.3 & 0.15 & Bal. \\
\hline
\end{tabular}


CNT ball-milling: Multi walled carbon nanotubes (MWCNT) with purity $>95 \%, 10-30 \mu \mathrm{m}$ in length, $5-10 \mathrm{~nm}$ in inside diameter and $20-30 \mathrm{~nm}$ in outside diameter, were purchased from US Research Nanomaterials, Inc. In order to improve the dispersion of CNT in electroless bath, as-received CNT were ball-milled for $3 \mathrm{~h}$ using a planetary ball-mill machine with Steel balls with different diameters have been used to mix CNT in cylindrical stainless steel jar, with a rotating speed and $5 \mathrm{~min}$ break intermitting every $10 \mathrm{~min}$ of milling to limit any heat build-up. Ethyl alcohol has been used in wet mixing. Figure 1 shows FESEM (Field Emission Scanning Electron Microscopy) in MIRA3 TESCAN company, images of as-received and ball milled CNTs. As it can be seen ball milled CNTs are shorter and more straight and therefore improves the dispersion of CNTs in the electroless bath.

In order to dispersed uniformly carbon nano-tubes in electroless Ni-B coatings and no agglomeration to provide stable and homogenous dispersion in the metallic matrix phase. Should used surfactants (sodium dodecyl sulfate (SDS) with CNT and together mixed with water by ultrasonic device for $45 \mathrm{~min}$.

Electroless bath preparation: After completion of preparing surfaces for coating, electroless bath were prepared for the process according to concentrations shown in Table 2. The Ni-B coating was deposited on AISI 4340 steel by an electroless plating process. The $\mathrm{pH}$ value of the plating bath was varied between 12-14. The electroless Ni-B plating was performed at $95 \pm 1^{\circ} \mathrm{C}$ for $60 \mathrm{~min}$. During plating the bath solution was agitated using a magnetic stirrer minimize the fluctuation of ionic concentration and to prevent localized overheating. The sample was rotated in two opposite directions alternatively every $10 \mathrm{~min}$ to obtain uniform coating thickness. Considering the coating process, for Ni-B-CNT deposition with different concentration of the CNTs $(0.35$, $0.7 \mathrm{~g} \mathrm{~L}^{-1} \mathrm{CNT}$ ), CNTs were firstly dispersed in an ultrasonic bath and were subsequently added to the $\mathrm{Ni}-\mathrm{B}$ prepared bath. A fresh electroless bath was applied for each test. Figure 2 shows the experimental setup for the electroless composite deposition. After the completion of

\begin{tabular}{ll} 
Table 2: Operating conditions for electroless bath & \\
\hline Bath composition & $\mathrm{g} \mathrm{L}^{-1}$ \\
\hline Nickel chloride (NiCl2.6H2O) & 24 \\
Sodium borohydride (NaBH4) & 0.8 \\
Ethylenediamine (98\%) (EDA) & $60 \mathrm{ML} \mathrm{L}^{-1}$ \\
Lead nitrate & 0.02 \\
Sodium hydroxide (NaOH) & 90 \\
Sodium Dodecyl Sulfate (SDS) & 2 \\
Carbon nanotube (CNT) & $0,0.35,0.7$ \\
Operating conditions & $(12-14) \mathrm{OR} 13$ \\
pH & $95^{\circ} \mathrm{C}$ \\
Temperature & $1 \mathrm{~h}$ \\
Time &
\end{tabular}
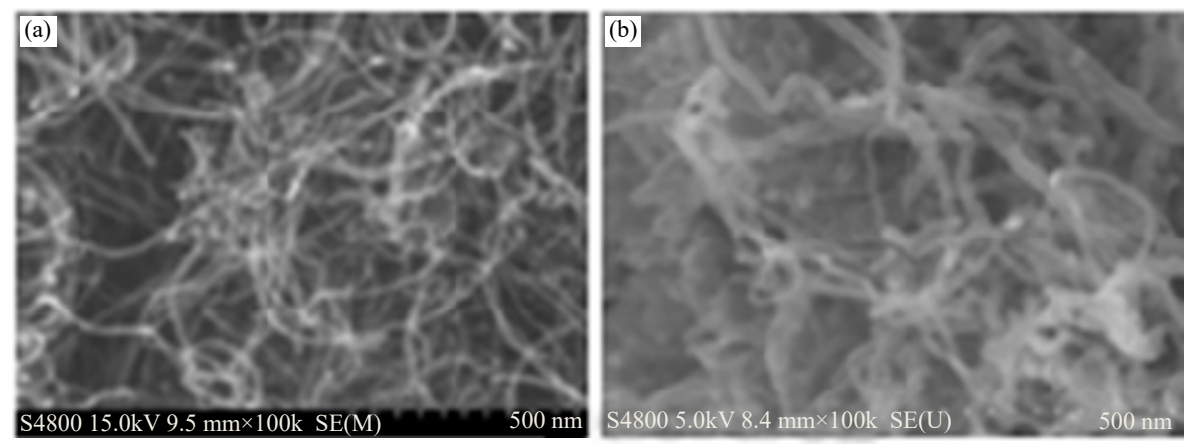

Fig. 1(a-b): FESEM images of (a) As-received CNT and (b) Ball milled CNT

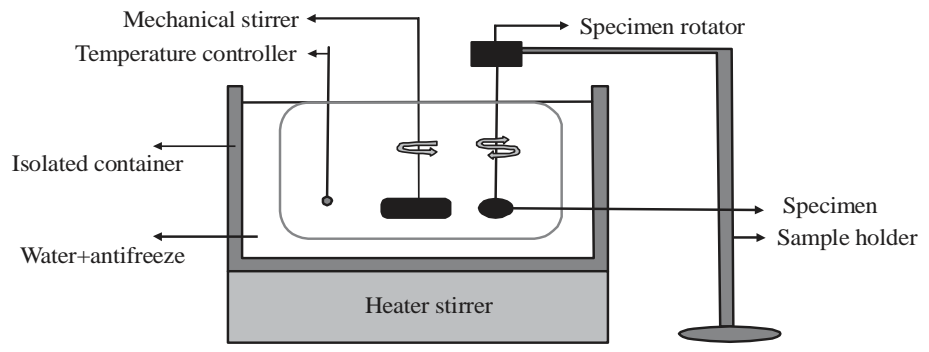

Fig. 2: Experimental setup for electroless deposition 
the process of coating, specimens were placed inside a vacuum oven, to dry for $30 \mathrm{~min}$, at a temperature $50^{\circ} \mathrm{C}$.

Plasma nitriding: After the deposition, all samples (Ni-B, Ni-B-0.35 $\mathrm{g} \mathrm{L}^{-1} \mathrm{CNT}$, Ni-B- $0.7 \mathrm{~g} \mathrm{~L}^{-1} \mathrm{CNT}$ ) were degreased using acetone and then were placed in a $5 \mathrm{~kW}$ conventional direct current plasma enhanced chemical vapor deposition (PECVD) chamber. working conditions for the plasma-nitrided treatment for electroless bath, was shown in Table 3. At the end of the treatment, samples were slowly cooled in the chamber to reach the room temperature.

Characterization: Microhardness of the coating layers were measured by using (TH-717 Vickers hardness tester), A load of $25 \mathrm{~g}$ was applied for $15 \mathrm{sec}$. Three readings were recorded for each specimen coated and one at the substrate. Then, the average value was taken. Wear test was conducted by Pin-on-disc technique according to ASTM G 99 standard. The test was performed at room temperature $25^{\circ} \mathrm{C}$ and relative humidity of about $40 \%$. The used load was $10 \mathrm{~N}$. Sliding velocity was $0.1 \mathrm{~min} \mathrm{sec}^{-1}$ and sliding distance was $500 \mathrm{~m}$. The disc was carbide steel. The specimens were weighed by a sensitive scale before and after the wear test to calculate the mass loss of coatings. The specific wear rate was calculated by the expression:

$$
\text { Ws }=\frac{\mathrm{W}}{\mathrm{L}}
$$

where, $w$ is the mass loss, $\mathrm{L}$ is the normal load and 1 is the sliding distance. The value of Surface roughness measurement was carried out for the coated samples before and after plasma nitriding treatment using a common parameter $\mathrm{Ra}$ in $\mu \mathrm{m}$. In this work, Surface roughness Tester HER210 Model was used to measure Ra with accuracy $0.05 \mu \mathrm{m}$ and the average of ten measurements was recorded. The coatings were examined for the identification of the crystalline phase. The phase of coating was identified with EQuinox 3000 X-ray diffraction (XRD), with $\mathrm{Cu} \mathrm{Ka}(\mathrm{X}=1.54187 \mathrm{~A})$ radiation and scanning range of 20 between $5^{\circ}$ and $118^{\circ}$ and operated at $40 \mathrm{kV}$ and $30 \mathrm{~mA}$ was utilized to identify the crystal structure of the samples before and after plasma nitriding treatment.

Table 3: Operating conditions of plasma nitriding treatment

\begin{tabular}{ll}
\hline Pluse Dc plasma nitriding (PPN) & Conditions \\
\hline $400{ }^{\circ} \mathrm{C}$ & Temperature $\left({ }^{\circ} \mathrm{C}\right)$ \\
$10^{-3}$ torr & Pressure \\
$400-500 \mathrm{~V}$ & discharge voltage \\
$8.9 \mathrm{kHz}$ & Frequency \\
$70(\%)$ & Duty cycle \\
$2-3$ & Current $(\mathrm{A})$ \\
$\left(50 \% \mathrm{~N}_{2}-50 \% \mathrm{H}_{2}\right)$ & Gas composition \\
4 & Duration $(\mathrm{h})$ \\
\hline
\end{tabular}

\section{RESULT AND DISCUSSION}

XRD characterization: XRD patterns of as-plated Ni-B shows are presented in Fig. 3. XRD pattern of as-deposited electroless Ni-B coating in Fig. 3a shows a broad peak which indicates an amorphous structure. Numerous researchers have reported an amorphous or semi-crystalline structure for as-plated Ni-B. Boron as an amorphous element prevents the nucleation of nickel phase (Rao et al., 2005). By adding CNTs to the electroless bath, it was observed that the peak broadening was reduced and thus the peak became sharper as the CNTs concentration increased in the electroless bath. It can be concluded by the results in Ni-B-CNT samples H+ ions are released from carboxylic groups at the surface of $\mathrm{CNTs}$ and the remaining $\mathrm{HCOO}$-ions act as a reducing agent and thus reduces the $\mathrm{Ni}$ ions. Therefore, $\mathrm{Ni}$ starts to nucleate on the crystal defects of CNTs which act as the nucleation site and the structure of as-plated Ni-B-CNT with increasing CNTs concentration became more semi-crystalline. Similar phenomena have been observed by adding $\mathrm{SiC}$ particles (Georgiza et al., 2017). After the plasma nitriding treatment, the structure of as-plated samples was changed in Fig. 4 from amorphous to crystalline state due to formation of $\mathrm{Ni}_{2} \mathrm{~B}$ and $\mathrm{Ni}_{3} \mathrm{~B}$ intermetallic compounds. It can be claimed that the presence of the $\mathrm{Ni}_{3} \mathrm{~B}$ phase is due to the decomposition of the unstable $\mathrm{Ni}_{2} \mathrm{~B}$ phase or it could be the result of the asymmetric distribution of boron with low concentration. The presence of local concentrations of boron higher than $6 \%$ by weight has probably caused the $\mathrm{Ni}_{2} \mathrm{~B}$ phase formation to occur. Plus, continuous bombardment of the cathodic stage with the positively charged ions led to an increase in the surface temperature of samples and ultimately to the growth of the $\mathrm{Ni}_{2} \mathrm{~B}$ and $\mathrm{Ni}_{3} \mathrm{~B}$ phase. The peak observed in all samples can probably be attributed to hexagonal boron nitride (BN) structure (Vitry et al., 2012). It can be claimed that sputtered boron atoms react with active nitrogen in plasma atmosphere and forms BN which is then deposited on the sample surface. For all samples, the XRD patterns illustrate that the Ni peak was shifted to lower angles. This change might be an indication of interstitial diffusion of the nitrogen atoms in

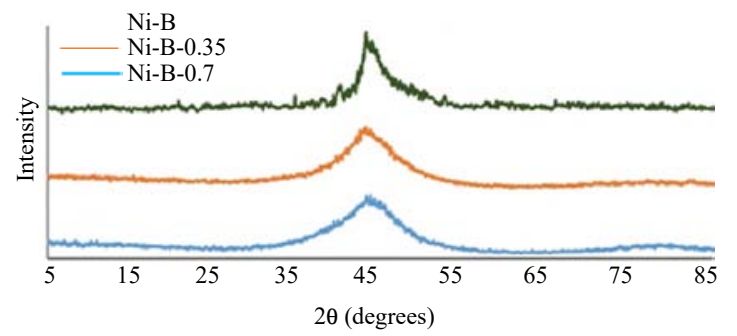

Fig.3:X-ray diffraction patterns of as-plated Ni-B and Ni-B-CNT samples 


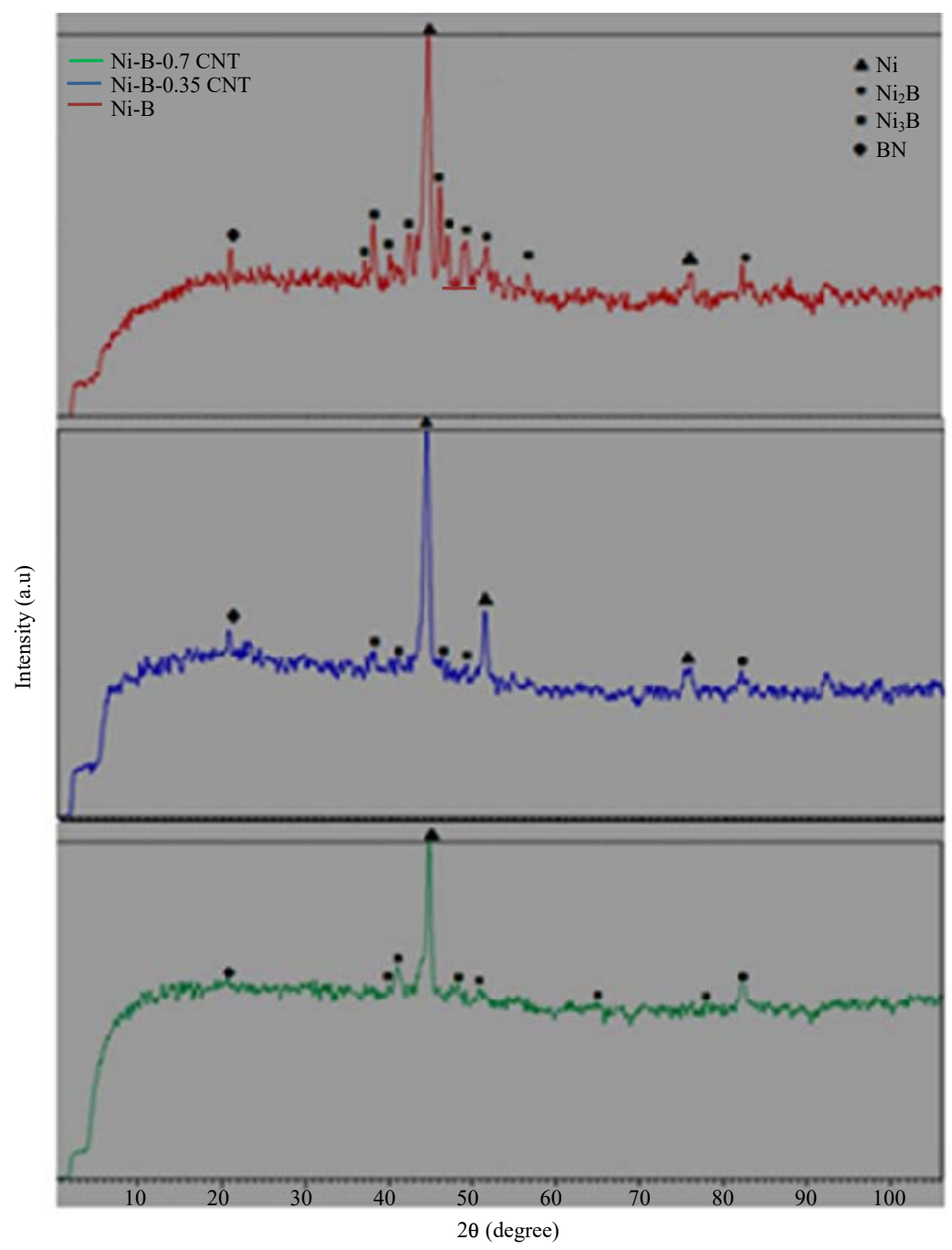

Fig. 4: X-ray diffraction patterns of plasma-nitrided Ni-B and Ni-B-CNT samples

the Ni matrix which could ultimately lead to an increase in the d-spacing by inducing the residual stress during the plasma nitriding process. Another reason could be the substitution of boron with nickel atoms during the treatment (Bekish et al., 2010).

Surface morpholog: The surface morphology of the as-plated samples is illustrated in Fig. 5. The smooth structure can be observed in Ni-B sample image in Fig. 5a and exhibits a cauliflower type structure. This kind of structure is useful in retaining lubricants under conditions of adhesive wear (Vitry and Bonin, 2017; Mukhopadhyay et al., 2017). During the particle distribution, a bigger portion of the CNTs were embedded in the matrix while the smaller portion were protruded from the coated surface; However, CNTs were observed at the surface of the sample containing $0.35 \mathrm{~g} \mathrm{~L}^{-1} \mathrm{CNT}$ in Fig. 5b. Moreover, in the sample containing $0.35 \mathrm{~g} \mathrm{~L}^{-1}$ of
CNTs, significant change in the morphology was witnessed, which seems logical and caused a more uniformly coated surface to be achieved since CNTs have the ability to fill the gaps and the crevices due to the low concentration of nanotubes. By increasing the concentration of CNTs to $0.7 \mathrm{~g} \mathrm{~L}^{-1}$ the size of the nodules grew. This could be associated with the raised concentration of reduced $\mathrm{Ni}$ in the electroless bath which could cause the crystal growth to overshadow nucleation in Fig. 5c. The existence of large particles in Ni-B-0.7 g L ${ }^{-1}$ CNT sample could be the result of the CNTs aggregation owing to the high concentration of them. The aggregation could lead to agglomeration of CNTs on the substrate and subsequently large particles at the surface of the samples could be formed owing to the nucleation of $\mathrm{Ni}$ on the agglomerated CNTs. In order to demonstrate the CNTs distribution more clearly, an image with higher magnification of the sample is also added in Fig. 5d. 

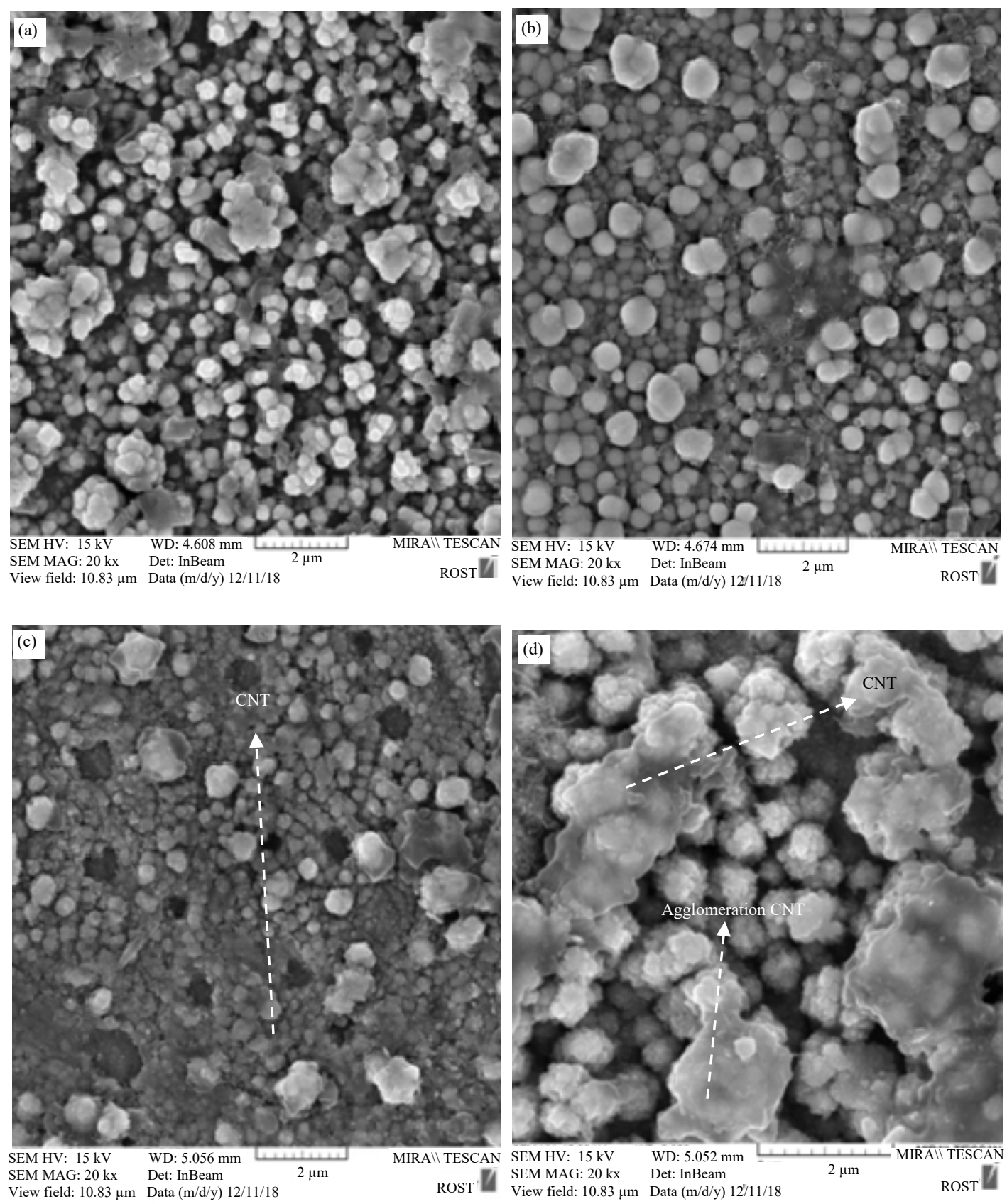

Fig. 5(a-d): FESEM images of electroless coated (a) Ni-B, (b) Ni-B-0.35 g L ${ }^{-1}$ CNT, (c) Ni-B-0.7 g L ${ }^{-1}$ CNT and (d) Higher magnification of Ni-B-0.7 $\mathrm{g} \mathrm{L}^{-1} \mathrm{CNT}$

Figure 6 FESEM observations of the plasma-nitrided samples show that the surface morphology of Ni-B was changed into a cauliflower-like structure and became more densified in Fig. 6a. The preferential deposition on defect sites of the surface at the beginning of the process might be the possible reason for the type of the structure seen (Vitry and Bonin, 2017; Anik et al., 2008). Figure 6b show sample containing $0.35 \mathrm{~g} \mathrm{~L}^{-1} \mathrm{CNT}$ similar densification was occurred. In fact, the growth of crystals which were initially nucleated at different preferred sites has caused $\mathrm{Ni}_{2} \mathrm{~B}, \mathrm{Ni}_{3} \mathrm{~B}$ and $\mathrm{BN}$ particles to coincide and cover the surface of the sample. Also, sputtering and re-deposition of the atoms have possibly caused the re-deposited compounds to fill the holes during the plasma nitriding treatment. The sample containing $0.7 \mathrm{~g} \mathrm{~L}^{-1} \mathrm{CNT}$ was consisted of coarser particles in 

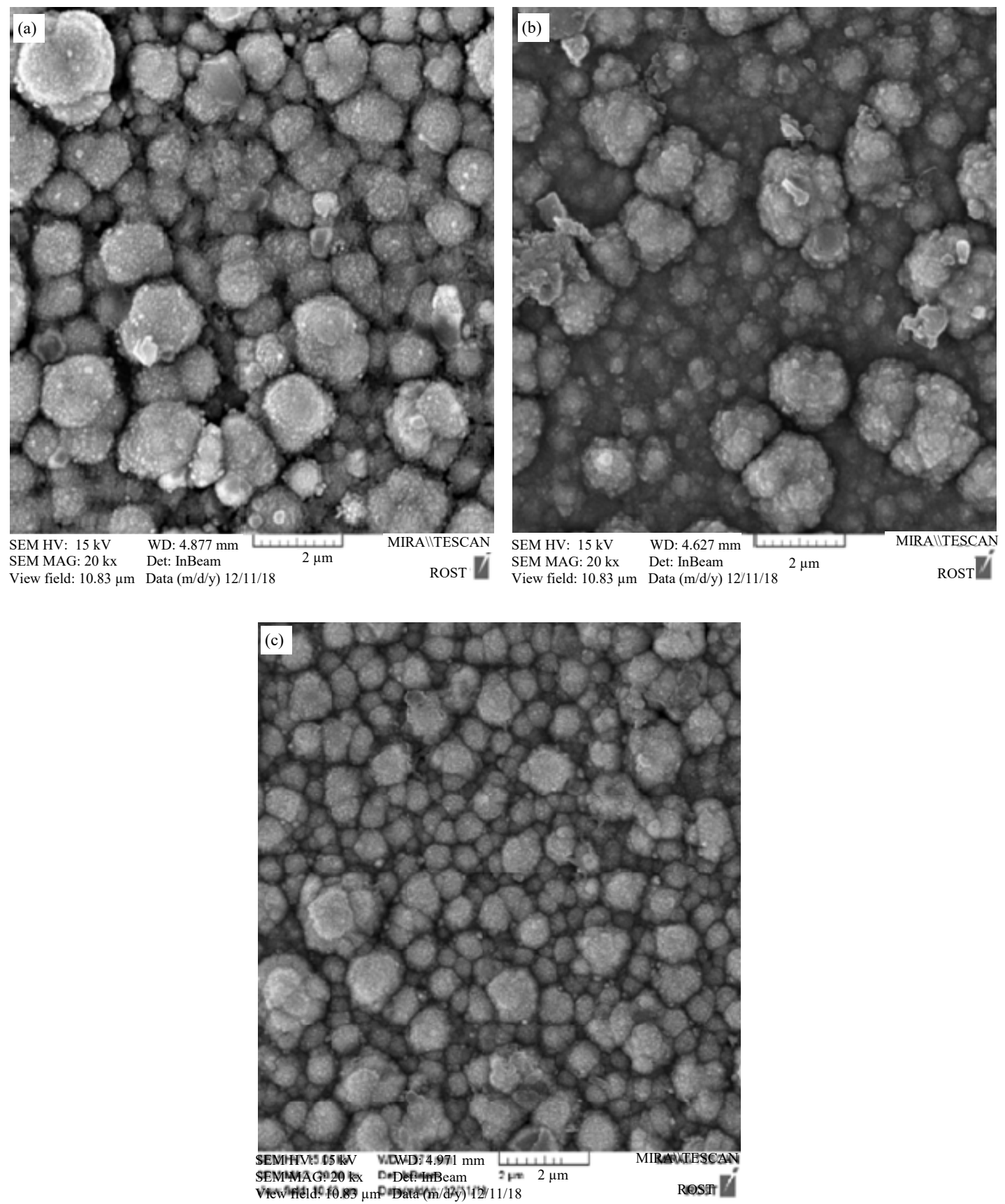

Fig. 6: FESEM images of plasma-nitrided (a) Ni-B, (b) Ni-B-0.35 g L ${ }^{-1} \mathrm{CNT}$, (c) Ni-B-0.7 g L ${ }^{-1}$ CNT

Fig. 6c. The agglomerated particles were observed to become 2 or 3 times larger after the plasma nitriding treatment owing to high concentration of CNTs which causes more nucleation of the nanoclusters and more growth rate in this sample. However, no evidence of the CNTs at the surface of this sample was observed. This could be attributed to the fact that, the continuous ion bombardment during the plasma nitriding process has removed the excessive amount of CNTs from the surface.
Surface roughness: Table 4 provides data on the roughness of the substrate, as-plated and plasma-nitrided samples. In previous study was noted that the Ni-B nodules are almost flat and uniformly dispersed in as-deposited condition. As it is indicated. raising CNTs concentration up to $0.7 \mathrm{~g} \mathrm{~L}^{-1}$ has led to a significant increase in the roughness. This is on the grounds that CNTs inhibit uniform growth of $\mathrm{Ni}$ and create asperities. In Ni-B-0.7 $\mathrm{g} \mathrm{L}^{-1} \mathrm{CNT}$ sample the roughness was noticed 
Table 4: Result of samples surface roughness

\begin{tabular}{lc} 
Sample & $\mathrm{Ra}(\mu)$ \\
\hline Substrate & 0.02 \\
Ni-B as-a plated & 0.10 \\
Ni-B-0.35 $\mathrm{g} \mathrm{L}^{-1}$ CNT as-a plated & 0.17 \\
Ni-B-0.7 $\mathrm{g} \mathrm{L}^{-1}$ CNT as-a plated & 0.25 \\
Ni-B as-a plasma-nitrided & 0.30 \\
Ni-B-0.35 g L-1 CNT as-a plasma-nitrided & 0.21 \\
Ni-B-0.7 $\mathrm{g} \mathrm{L}^{-1}$ CNT as-a plasma-nitrided & 0.40 \\
\hline
\end{tabular}

Table 5: Results of average coefficient of friction, mass loss and specific wear rate of coated samples.

\begin{tabular}{|c|c|c|c|}
\hline Sample & Coefficient of friction & Mass loss (mg) & Specific wear rate $(\mathrm{kg} / \mathrm{N}-\mathrm{M})_{\times} 10^{-6}$ \\
\hline Substrate & 0.68 & 1.70 & $3.4 \mathrm{E}-4$ \\
\hline Ni-B as-a plated & 0.60 & 0.50 & $1 \mathrm{E}-4$ \\
\hline Ni-B- $0.35 \mathrm{~g} \mathrm{~L}^{-1}$ CNT as-a plated & 0.51 & 0.45 & $0.9 \mathrm{E}-4$ \\
\hline Ni-B- $0.7 \mathrm{~g} \mathrm{~L}^{-1}$ CNT as-a plated & 0.59 & 0.55 & $1.1 \mathrm{E}-4$ \\
\hline Ni-B as-a plasma-nitrided & 0.45 & 0.20 & $0.4 \mathrm{E}-4$ \\
\hline Ni-B- $0.35 \mathrm{~g} \mathrm{~L}^{-1}$ CNT as-a plasma-nitrided & 0.30 & 0.05 & $0.1 \mathrm{E}-4$ \\
\hline Ni-B- 0.7 g L$^{-1}$ CNTas-a plasma-nitrided & 0.41 & 0.40 & $0.8 \mathrm{E}-4$ \\
\hline
\end{tabular}

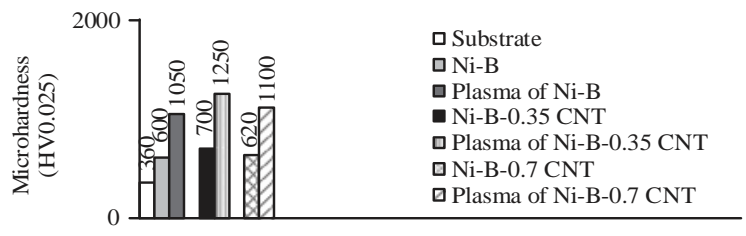

Fig. 7: Microhardness results of as-plated and plasmanitrided of samples surface

to be much higher in comparison with the other samples, owing to the high concentration of CNTs which could causes agglomeration. After plasma nitriding, the surface roughness $(\mathrm{Ra})$ of all as-plated samples were increased, surface roughness of the CPN coating is more than as-plated. An increase in the surface roughness by plasma nitriding was also observed in the previous studies (Sohi et al., 2010; Singh et al., 2006). Three possible explanations could be provided for this result. First, after the plasma nitriding process, the crystal growth of $\mathrm{Ni}_{2} \mathrm{~B}$, $\mathrm{Ni}_{3} \mathrm{~B}$ and $\mathrm{BN}$ phases in the Ni matrix created asperities and thus the surface roughness increased. Second, the sputtering effect during the plasma-nitriding process, caused by the positive nitrogen and hydrogen ion bombardment, affected the roughness of the samples. Third, this resulted due to the re-deposition of sputtered material on the surface.

Microhardness: Figure 7 shows the surface microhardness of the as-plated samples. As can be observed, the reinforcing ability of CNTs had an impact on increasing the surface microhardness, especially in Ni-B-0.35 g L ${ }^{-1}$ CNT sample. This can be attributed to the uniform distribution and reinforcement of CNTs in this sample. In Ni-B-0.7 $\mathrm{g} \mathrm{L}^{-1} \mathrm{CNT}$ the hardness was found to be lower in comparison with the sample containing $0.35 \mathrm{~g} \mathrm{~L}^{-1} \mathrm{CNT}$ because of the higher concentration of CNTs, segregation which occurred in the composite caused a reduction in the microhardness of composite coated layer (Umeda et al., 2015).
Wear behavior: Table 5 shows the average coefficient of friction and specific wear rate of as-plated, heat treatment and plasma-nitrided samples. It can be observed that the friction coefficient has a direct relation with the specific wear rate. Plasma-nitrided Ni-B- $0.35 \mathrm{~g} \mathrm{~L}^{-1} \mathrm{CNT}$ had the lowest specific wear rate in comparison with the other samples due to several reasons such as higher microhardness, lower coefficient of friction, smaller grain size and most importantly homogenous distribution of $\mathrm{Ni}_{2} \mathrm{~B}, \mathrm{Ni}_{3} \mathrm{~B}$ and $\mathrm{BN}$ particles.

Figure 8 shows FESEM analysis of the samples worn surfaces after wear test. The improvement of wear resistance is obvious. In Fig. 8-9a-c deep and wide wear track, Ni-B sample lamellar debris particles indicate the delamination occurred during the wear test in Fig. 8-9a. The high solubility of iron from the counter part in nickel from the coated surface resulted in successive welding and detaching of surface and counterpart which ultimately caused delamination in the sample. As has been reported by numerous researchers, abrasion and adhesion might be the main mechanism affecting the sample (Correa et al., 2013; Yamamoto et al., 2014). By increasing the CNTs concentration up to $0.35 \mathrm{~g} \mathrm{~L}^{-1}$ fine grooves along the sliding direction, was observed in Fig. 8-9 b. According to Fig. 10, chemical analysis of the elements remained on the wear track illustrated a decreased amount of iron in comparison with Ni-B sample. This might be due to the fact that the cut off CNTs act as ball bearing spacer and could prevent direct contact of the coated surface and the counterpart and thus the diffusion of the iron element into the coated surface could decrease (Bastwros et al., 2013). Therefore, by increasing the concentration of CNTs up to 0.35 , due to the presence of a more lubricated surface, the contact of the surface and the counterpart lessens and the wear resistance could increase. Studying NiB-0.7 $\mathrm{g} \mathrm{L}^{-1}$ CNT sample in Fig. 8-9c, deeper groves were observed owing to the separation of conglomerate particles that had weak bonding energy with the surface during the wear test (Kim et al., 2009). 

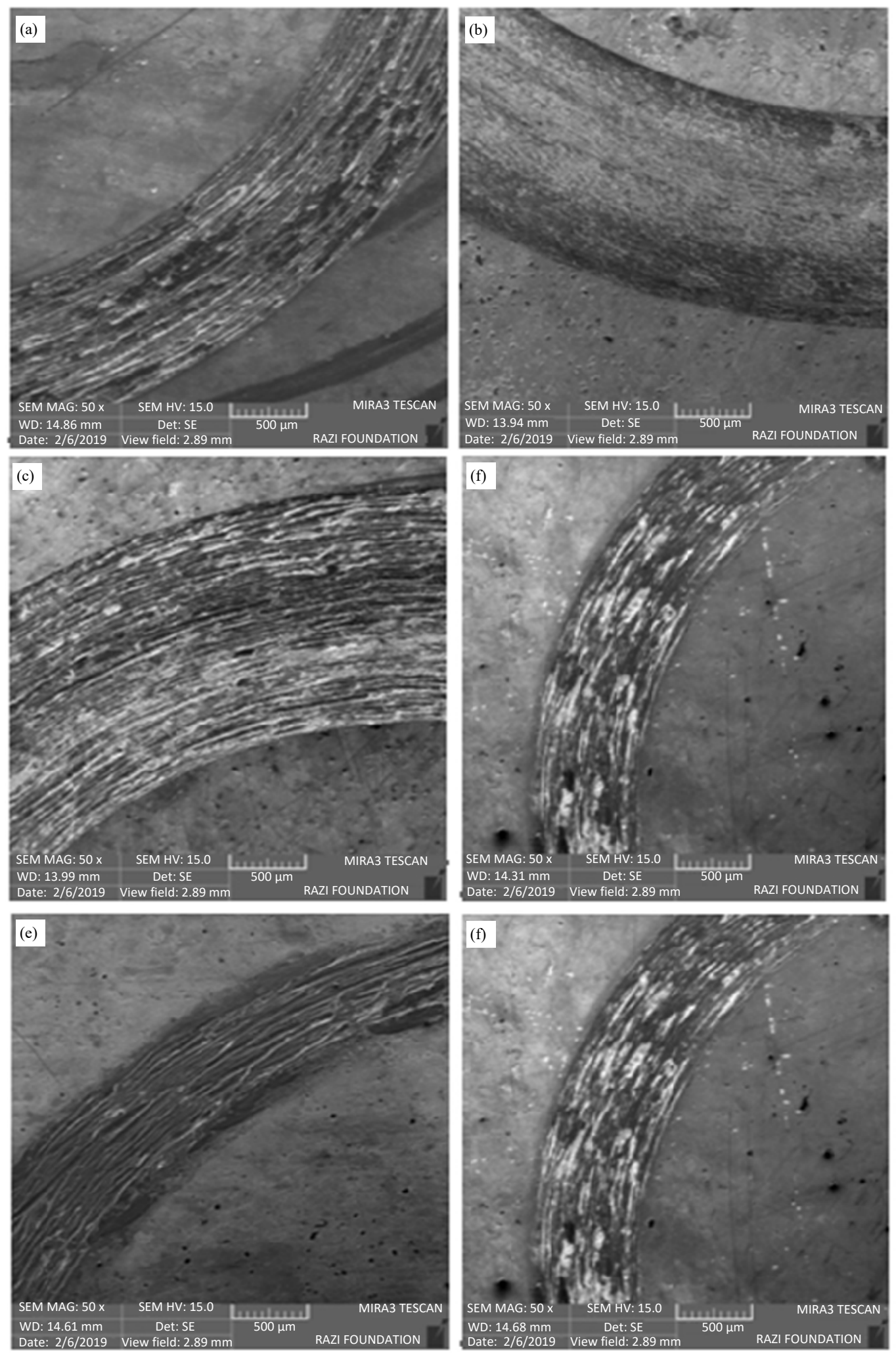

Fig. 8(a-f): FESEM micrographs of wear track the of (a) Ni-B, (b) Ni-B-0.35 g L ${ }^{-1}$ CNT, (c) Ni-B-0.7 g L ${ }^{-1} \mathrm{CNT}_{\text {as- }}$ plated and (d) Ni-B, (e) Ni-B-0.35 $\mathrm{g} \mathrm{L}^{-1} \mathrm{CNT}$ and (f) Ni-B-0.7 $\mathrm{g} \mathrm{L}^{-1} \mathrm{CNT}$ plasma-nitrided samples 

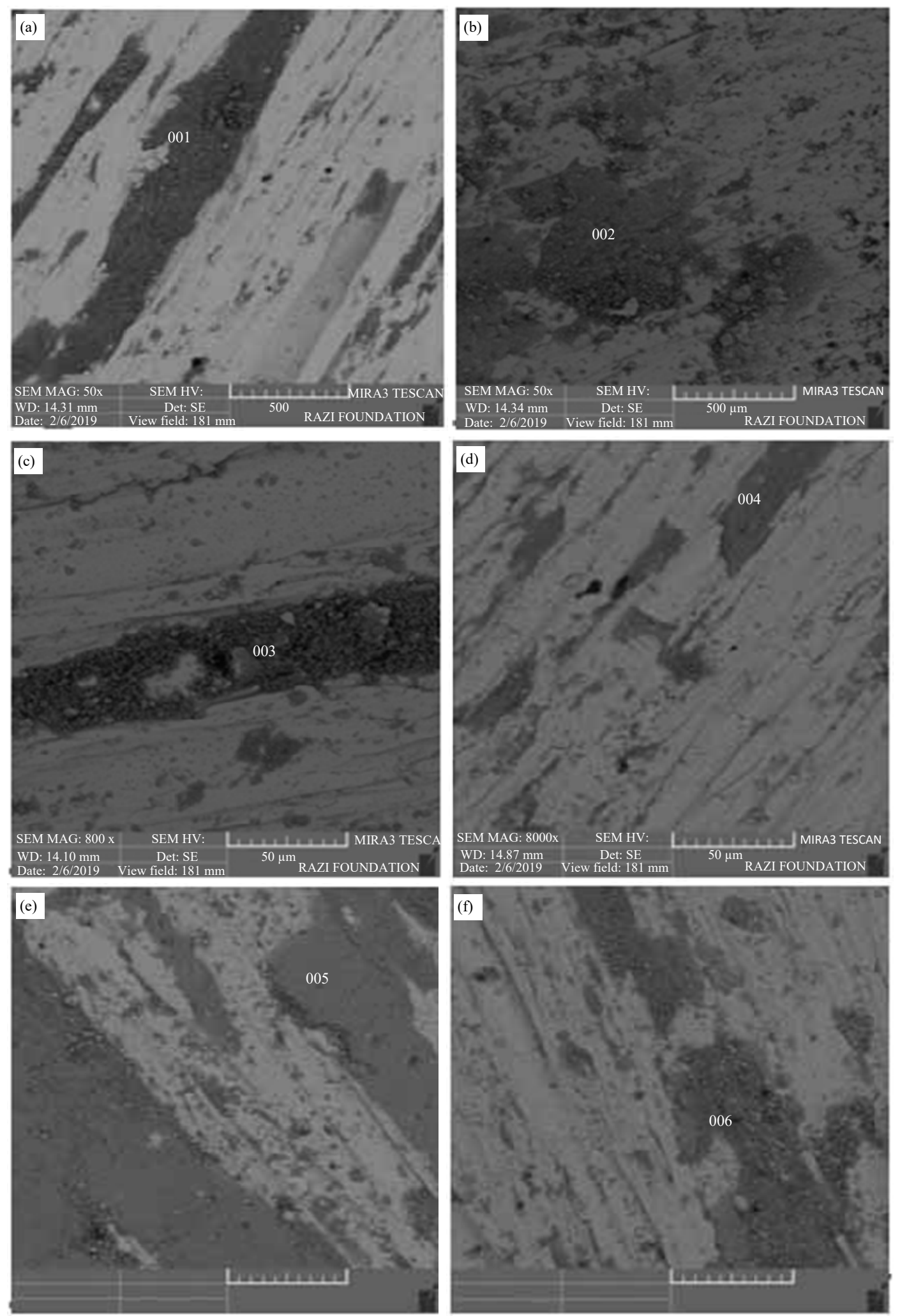

Fig. 9(a-f): FESEM micrographs of worn surfaces of the (a) Ni-B, (b) Ni-B-0.35 g L ${ }^{-1}$ CNT, (c) Ni-B- $0.7 \mathrm{~g} \mathrm{~L}^{-1}$ CNT as-plated and (d) Ni-B, (e) Ni-B-0.35 g L ${ }^{-1} \mathrm{CNT}$ and (f) Ni-B-0.7 $\mathrm{g} \mathrm{L}^{-1} \mathrm{CNT}$ plasma-nitrided samples 
(a)
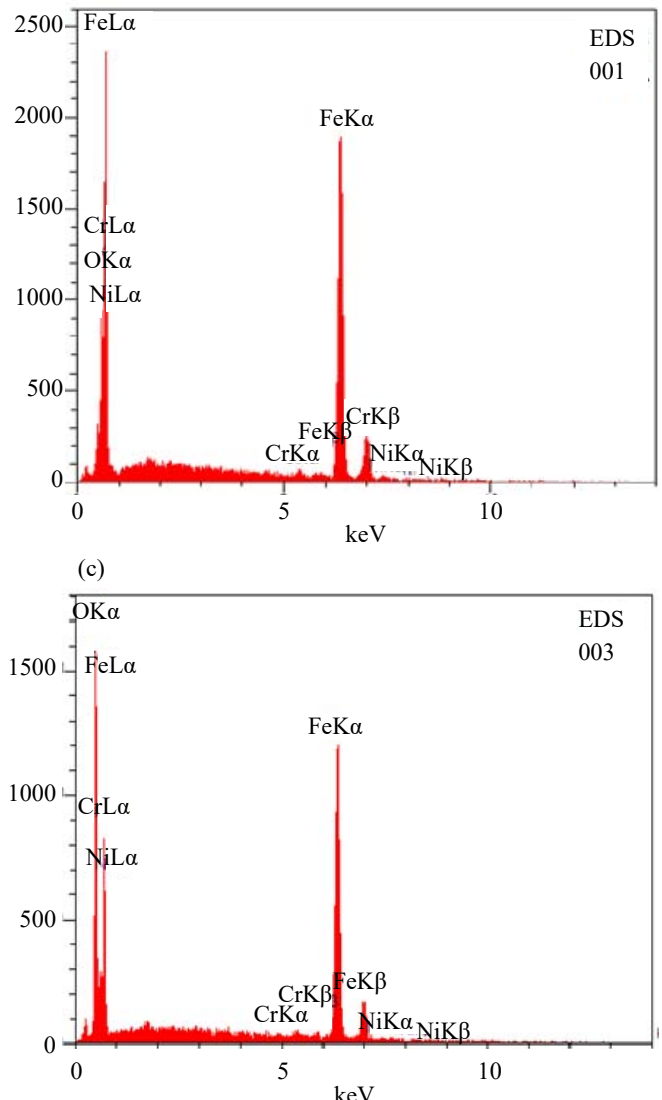

(e)

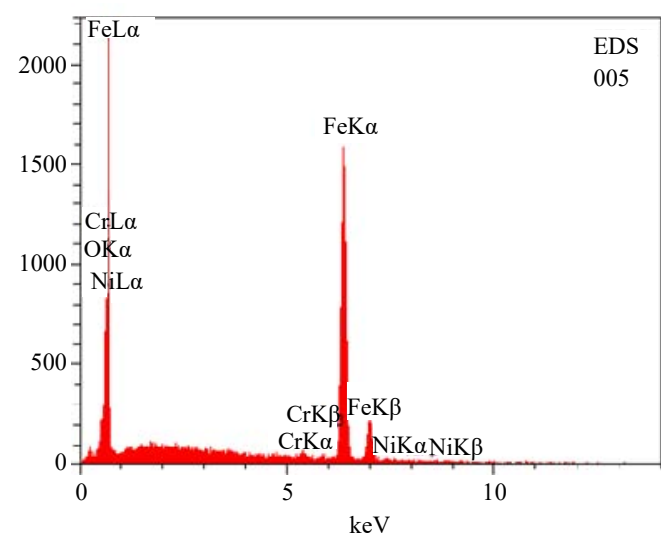

Fig. 10(a-f): EDS analysis of worn surface of samples

After nitriding the wear track became narrower and shallower Besides, the formation of the relative dark and smooth oxidized pitch as well as the morphologies of the wear track indicated the domination of oxidation wear and slight abrasion in the wear process of this sample. The EDS results proves that the amount of oxygen in the plasma-nitrided Ni-B-CNT samples was lower in comparison with the Ni-B sample. This could be ascribed
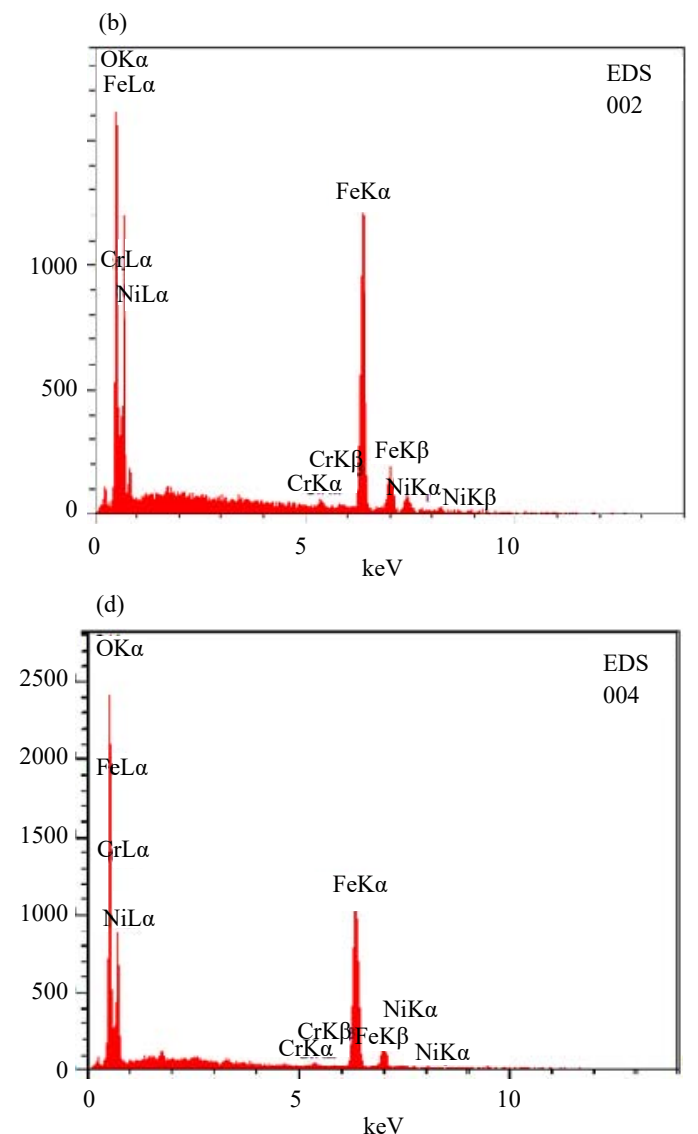

(f)

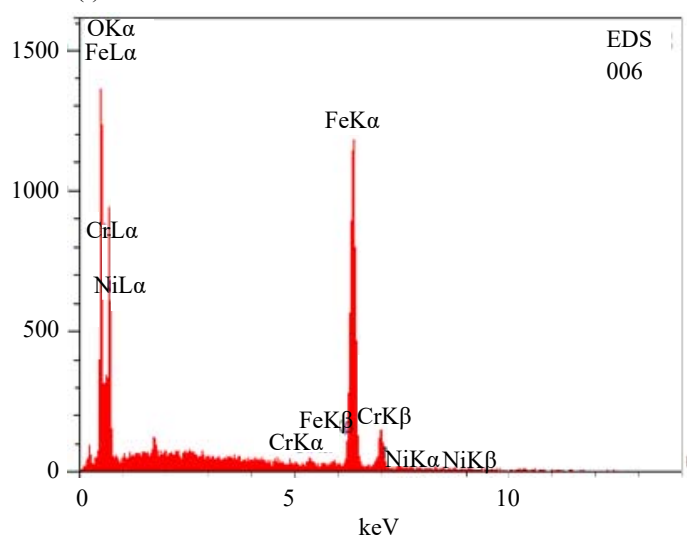

to the fact that CNTs could prevent excessive heat generation during the wear test; thus, the plastic deformation was decreased and a smooth surface with fine grooves and lower debris were observed in the FESEM image Fig. 8-9e. Higher microhardness values and the uniform distribution of particles in Ni matrix which helped transfer the counterpart force from $\mathrm{Ni}$ to the CNTs ultimately resulted in higher wear resistance in 
the plasma-nitrided Ni-B-0.35 $\mathrm{g} \mathrm{L}^{-1}$ CNT sample (Bastwros et al., 2013). Moreover, lower grain size in comparison with the other plasma-nitrided samples, caused the grain peeling mechanism to be decreased owing to high interfacial strength (Zhai et al., 2017), was another reason why Ni-B-0.35 $\mathrm{g} \mathrm{L}^{-1}$ CNT had the smoothest wear trace Fig. 8-9e. Studying the Ni-B- $0.7 \mathrm{~g} \mathrm{~L}^{-1}$ CNT sample, indicated that the presence of fine debris after the wear test can be ascribed to the coarse particles cut from the surface and crushed due to the pin continuously move on the surface Fig. 8-9f. The particles movement leaves some scratch on the surface of the sample which ultimately reduces the wear properties.

\section{REFERENCES}

Afroukhteh, S., C. Dehghanian and M. Emamy, 2012. Corrosion behavior of Ni-P/nano-TiC composite coating prepared in electroless baths containing different types of surfactant. Prog. Nat. Sci.: Mater. Int., 22: 480-487.

Anik, M., E. Korpe and E. Sen, 2008. Effect of coating bath composition on the properties of electroless nickel-boron films. Surf. Coat. Technol., 202: 1718-1727.

Bastwros, M.M.H., A.M.K. Esawi and A. Wifi, 2013. Friction and wear behavior of Al-CNT composites. Wear, 307: 164-173.

Bekish, Y.N., S.K. Poznyak, L.S. Tsybulskaya and T.V. Gaevskaya, 2010. Electrodeposited Ni-B alloy coatings: Structure, corrosion resistance and mechanical properties. Electrochim. Acta, 55: 2223-2231.

Boccaccini, A.R. andI. Zhitomirsky, 2002. Application of electrophoretic and electrolytic deposition techniques in ceramics processing. Curr. Opin. Solid State Mater. Sci., 6: 251-260.

Brenner, A. and G.E. Riddell, 1946. Nickel plating on steel by chemical reduction. J. Res., 37: 31-34.

Bulbul, F., H. Altun, V. Ezirmik and O. Kucuk, 2012. Investigation of structural, tribological and corrosion properties of electroless Ni-B coating deposited on 316L stainless steel. Proc. Inst. Mech. Eng. Part J. J. Eng. Tribol., 27: 629-639.

Carpenter, C.R., P.H. Shipway and Y. Zhu, 2011. Electrodeposition of nickel-carbon nanotube nanocomposite coatings for enhanced wear resistance. Wear, 271: 2100-2105.

Correa, E., A.A. Zuleta, L. Guerra, M.A. Gomez and J.G. Castano et al., 2013. Tribological behavior of electroless Ni-B coatings on Magnesium and AZ91D alloy. Wear, 305: 115-123.

Georgiza, E., V. Gouda and P. Vassiliou, 2017. Production and properties of composite electroless Ni-B-SiC coatings. Surf. Coat. Technol., 325: 46-51.
Hassan, H.B. and Z.A. Hamid, 2011. Electroless Ni-B supported on carbon for direct alcohol fuel cell applications. Int. J. Hydrogen Energy, 36: 849-856.

Hatipoglu, G., M. Kartal, M. Uysal, T. Cetinkaya and H. Akbulut, 2016. The effect of sliding speed on the wear behavior of pulse electro Co-deposited Ni/MWCNT nanocomposite coatings. Tribol. Int., 98: 59-73.

He, Y., S.C. Wang, F.C. Walsh, Y.L. Chiu and P.A.S. Reed, 2016. Self-lubricating Ni-P-MoS composite coatings. Surf. Coat. Technol., 307: 926-934.

Kim, I.Y., J.H. Lee, G.S. Lee, S.H. Baik, Y.J. Kim and Y.Z. Lee, 2009. Friction and wear characteristics of the carbon nanotube-aluminum composites with different manufacturing conditions. Wear, 267: 593-598.

Krishnaveni, K., T.S.N.S. Narayanan and S.K. Seshadri, 2005. Electroless Ni-B coatings: Preparation and evaluation of hardness and wear resistance. Surf. Coat. Technol., 190: 115-121.

Li, C., Y. Wang and Z. Pan, 2013. Wear resistance enhancement of electroless nanocomposite coatings via incorporation of alumina nanoparticles prepared by milling. Mater. Des., 47: 443-448.

Liu, Z. and W. Gao, 2006. Electroless nickel plating on AZ91 Mg alloy substrate. Surf. Coat. Technol., 200: 5087-5093.

Melk, L., J.J.R. Rovira, M.L. Antti and M. Anglada, 2015. Coefficient of friction and wear resistance of zirconia-MWCNTs composites. Ceram. Int., 41: 459-468.

Monteiro, O.R., S. Murugesan and V. Khabashesku, 2015. Electroplated Ni-B films and Ni-B metal matrix diamond nanocomposite coatings. Surf. Coat. Technol., 272: 291-297.

Mukhopadhyay, A., T.K. Barman and P. Sahoo, 2017. Tribological behavior of Sodium borohydride reduced electroless nickel alloy coatings at room and elevated temperatures. Surf. Coat. Technol., 321: 464-476.

Munkhbayar, B., M.J. Nine, J. Jeoun, M. Bat-Erdene, $\mathrm{H}$. Chung and H. Jeong, 2012. Influence of dry and wet ball milling on dispersion characteristics of the multi-walled carbon nanotubes in aqueous solution with and without surfactant. Powder Technol., 234: 132-140.

Narayanan, T.S.N.S., A. Stephan and S. Guruskanthan, 2004. Electroless Ni-Co-B ternary alloy deposits: Preparation and characteristics. Surf. Coat. Technol., 179: 56-62.

Niksefat, V. and M. Ghorbani, 2015. Mechanical and electrochemical properties of ultrasonic-assisted electroless deposition of $\mathrm{Ni}-\mathrm{B}-\mathrm{TiO}_{2}$ composite coatings. J. Alloys Compd., 633: 127-136. 
Puchy, V., P. Hvizdos, J. Dusza, F. Kovac, F. Inam and M. J. Reece, 2013. Wear resistance of $\mathrm{Al}_{2} \mathrm{O}_{3}$-CNT ceramic nanocomposites at room and high temperatures. Ceram. Int., 39: 5821-5826.

Rao, Q.L., G. Bi, Q.H. Lu, H.W. Wang and X.L. Fan, 2005. Microstructure evolution of electroless Ni-B film during its depositing process. Applied Surf. Sci., 240: 28-33.

Riddle, Y.W. and T.O. Bailerare, 2005. Friction and wear reduction via an Ni-B electroless bath coating for metal alloys. J. Miner., 57: 40-45.

Riedel, A., 1989. Electroless Nickel Plating. Finishing Publication Ltd., London, England, UK.

Sahoo, P. and S.K. Das, 2011. Tribology of electroless nickel coatings-a review. Mater. Des., 32: $1760-1775$.

Schlesinger, H.I. and H.C. Brown, 1945. Preparation of alkali metal compounds. US Patent US2461661A. United States Patent Office, USA.

Singh, G.P., J. Alphonsa, P.K. Barhai, P.A. Rayjada, P.M. Raole and S. Mukherjee, 2006. Effect of surface roughness on the properties of the layer formed on AISI 304 stainless steel after plasma nitriding. Surf. Coat. Technol., 200: 5807-5811.

Sohi, M.H., M. Ebrahimi, A.H. Raouf and F. Mahboubi, 2010. Effect of plasma nitrocarburizing temperature on the wear behavior of AISI 4140 steel. Surf. Coat. Technol., 205: S84-S89.

Thiemig, D. and A. Bund, 2008. Characterization of electrodeposited $\mathrm{Ni}^{-\mathrm{TiO}_{2}}$ nanocomposite coatings. Surf. Coat. Technol., 202: 2976-2984.

Tsai, P.C., Y.R. Jeng, J.T. Lee, I. Stachiv and P. Sittner, 2017. Effects of carbon nanotube reinforcement and grain size refinement mechanical properties and wear behaviors of carbon nanotube/copper composites. Diamond Relat. Mater., 74: 197-204.

Umeda, J., B. Fugetsu, E. Nishida, H. Miyaji and K. Kondoh, 2015. Friction behavior of networkstructured CNT coating on pure titanium plate. Applied Surf. Sci., 357: 721-727.

Vitry, V. and L. Bonin, 2017. Formation and characterization of multilayers borohydride and hypophosphite reduced electroless nickel deposits. Electrochim. Acta, 243: 7-17.

Vitry, V., A. Sens, A.F. Kanta and F. Delaunois, 2012. Experimental study on the formation and growth of electroless nickel-boron coatings from borohydridereduced bath on mild steel. Applied Surf. Sci., 263: 640-647.
Vitry, V., A.F. Kanta and F. Delaunois, 2011. Mechanical and wear characterization of electroless nickel-boron coatings. Surf. Coat. Technol., 206: 1879-1885.

Vitry, V., A.F. Kanta andF. Delaunois, 2012. Application of nitriding to electroless nickel-boron coatings: Chemical and structural effects; mechanical characterization; corrosion resistance. Mater. Des., 39: 269-278.

Wan, Y., Y. Yu, L. Cao, M. Zhang, J. Gao and C. Qi, 2016. Corrosion and tribological performance of PTFE-coated electroless nickel boron coatings. Surf. Coat. Technol., 307: 316-323.

Wang, Q., M. Callisti, A. Miranda, B. McKay and I. Deligkiozi et al., 2016. Evolution of structural, mechanical and tribological properties of Ni-P/MWCNT coatings as a function of annealing temperature. Surf. Coat. Technol., 302: 195-201.

Wang, Z.C., F. Jia, L. Yu, Z.B. Qi, Y. Tang and G.L. Song, 2012. Direct electroless nickel-boron plating on AZ91D magnesium alloy. Surf. Coat. Technol., 206: 3676-3685.

Wu, L.P., J.J. Zhao, Y.P. Xie and Z.D. Yang, 2010. Progress of electroplating and electroless plating on magnesium alloy. Trans. Nonferrous Met. Soc. China, 20: s630-s637.

Wu, P., H.M. Du, X.L. Chen, Z.Q. Li, H.L. Bai and E.Y. Jiang, 2004. Influence of WC particle behavior on the wear resistance properties of Ni-WC composite coatings. Wear, 257: 142-147.

Xuan, T.P., L. Zhang and Q.H. Huang, 2006. Crystallization behavior of electroless Co-Ni-B alloy plated in magnetic field in presence of cerium. Trans. Nonferrous Met. Soc. China, 16: 363-367.

Yamamoto, G., K. Shirasu, Y. Nozaka, Y. Sato, T. Takagi and T. Hashida, 2014. Structure-property relationships in thermally-annealed multi-walled carbon nanotubes. Carbon, 66: 219-226.

Yang, Y., W. Chen, C. Zhou, H. Xu and W. Gao, 2011. Fabrication and characterization of electroless $\mathrm{Ni}-\mathrm{P}-\mathrm{ZrO}_{2}$ nano-composite coatings. Applied Nanosci., 1: 19-26.

Yu, M.F., O. Lourie, M.J. Dyer, K. Moloni, T.F. Kelly and R.S. Ruoff, 2000. Strength and breaking mechanism of multiwalled carbon nanotubes under tensile load. Science, 287: 637-640.

Zhai, W., N. Srikanth, L.B. Kong and K. Zhou, 2017. Carbon nanomaterials in tribology. Carbon, 119: 150-171.

Zhou, M., Y. Mai, H. Ling, F. Chen, W. Lian and X. Jie, 2018. Electrodeposition of CNTs/copper composite coatings with enhanced tribological performance from a low concentration CNTs colloidal solution. Mater. Res. Bull., 97: 537-543. 